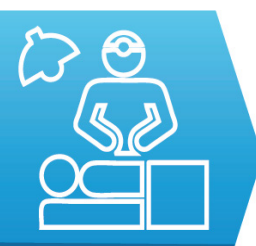

SURGERY
1) $2^{\text {nd }}$ Surgery Department, Mureș County Emergency University Hospital, Târgu Mureș, Romania

2) University of Medicine and Pharmacy, Târgu Mureș, Romania

3) Orthopedic and Traumatology Department, Mureș County Emergency University Hospital, Târgu Mureș, Romania
DOI: $10.15386 / \mathrm{mpr}-1648$

Manuscript received: 08.04.2020

Received in revised form: 21.05 .2020

Accepted: 09.06.2020

Address for correspondence:

salatatiana@yahoo.com

This work is licensed under a Creative Commons Attribution-NonCommercialNoDerivatives 4.0 International License

\title{
Safety of anastomotic techniques and consequences of anastomotic leakage in patients with colorectal cancer: a single surgeon experience
}

\author{
Etele Élthes ${ }^{1,2}$, Daniela Sala ${ }^{1,2}$, Radu Mircea Neagoe ${ }^{1,2}$, Kálmán Sárdi ${ }^{1}$, \\ János Székely ${ }^{3}$
}

\begin{abstract}
Introduction. Colorectal cancer is a common type of malignant disease of the digestive tract. Anastomotic leakage (AL) still represents a serious complication in gastrointestinal surgery, associated with high morbidity and mortality.

Methods. We conducted a retrospective case-control study and analyzed a single surgeon's data about 359 patients treated for colorectal cancer. Patients were divided as follows: Study Group (patients with AL - 37 patients) and Control Group (patients without AL - 322 patients). Surgical and anastomotic technique-related information was processed.

Results. Surgical procedures for right sided colon tumors resulted in a significantly lower rate of anastomotic leakage $(\mathrm{P}=0.0231)$. For left sided colectomies end to end handsewn double layer anastomosis presented decreased odds $(\mathrm{OR}=0.176)$. For sigmoid segmental resection end to end anastomotic techniques developed low rate of fistula formation (handsewn - $\mathrm{OR}=0.593$, stapled - $\mathrm{OR}=0.685$ ). Performing Dixon type surgical interventions, anastomotic techniques seemed without influence on anastomotic leak appearance (handsewn and stapled), although distal anastomoses were identified as significant risk factors for fistula formation $(\mathrm{P}=0.0017)$. In order to perform subtotal colectomy, side to side sutures (handsewn and stapled) seemed safe choices for anastomotic procedure $(\mathrm{P}=0.0073)$. Patient with anastomotic leakage suffered a significantly longer hospital stay $(\mathrm{P}=0.0079)$, presented higher rate of surgical reintervention $(\mathrm{P}=0.0001)$, increased mortality $(\mathrm{P}=0.0001)$ and elevated hospitalization costs $(\mathrm{P}=0.0079)$.

Conclusion. Postoperative complications like anastomosis leakage significantly increase hospitalization period, necessity of surgical reintervention, mortality and financial costs. In order to avoid these unpleasant events, bowel anastomoses require standardization during surgery.
\end{abstract}

Keywords: colorectal cancer, anastomotic leak, surgical anastomosis, safety, risk factors

\section{Introduction}

Colorectal cancer (CRC) represents a common type of pathology of the digestive tract, affecting nearly $10 \%$ of all patients suffering from malignant disease and resulting in a high percentage of cancer-related deaths. Its incidence is constantly increasing, making surgical procedures for colon tumors more and more common. Anastomotic leakage
(AL) represents a serious complication in gastrointestinal surgery, associated with high morbidity and mortality. Fistula formation is highly influenced by the localization of tissue fusion, it occurs more frequently in low rectal anastomosis, less common in colo-colonic anastomoses and it occurs in $0.02-4 \%$ of patients with entero-colonic anastomosis. Furthermore, it represents a complication that requires 
additional treatments strongly affecting the economic outcomes. In order to minimize occurrence of this major complication, it is crucial to be aware of the safest tissue fusion techniques and the possible impacts on postoperative evolution [1-4].

\section{Methods}

\section{Aim of study and patient selection}

Standardization of surgical procedures represents an important objective for the future, therefore, evaluating safety of anastomoses used in colorectal surgery represents the primary objective of the study. Meantime, investigating the effects of suture failure on patients short-term postoperative outcome constituted our secondary goal.

We conducted a retrospective case-control study at the $2^{\text {nd }}$ Surgery Department of Mureș County Emergency Clinical Hospital from Târgu Mureş, where 359 patients were treated for colorectal cancer between January 2016 and December 2019. All patients underwent surgery and benefited of removal of the primary tumor and reconstruction of bowel continuity with different anastomotic techniques. In order to reduce the impact of external factors like habits and preferences of surgeons on the present study, data were selected from a single surgeon with many years of professional experience. Exclusion criteria included surgical interventions in emergency conditions and all cases during which anastomosis formation was not possible, stoma formation was required during surgery. For data selection patients' approval were obtained.

Establishment of study groups and data collection

In the first part of the study, our major goal was to evaluate the safety of anastomoses used in the treatment of colorectal cancer and identify the most suitable anastomotic methods for each segment of the large bowel (right colon, left colon, sigmoid colon and rectosigmoid junction - rectum). Major surgical interventions were identified such as: right hemicolectomy, left hemicolectomy, Reybard procedure, Dixon operation and subtotal colectomy. Regarding anastomotic methods, three techniques were separated: entero-colonic, colo-colonic and colo-rectal. Depending on the presence of anastomotic failure, patients were divided as follows: Study Group (patients with AL) - 37 patients with postoperative anastomotic leak and Control Group (patients without AL) - 322 patients who did not develop this feared complication in the postoperative period. During data analysis, mainly surgical and anastomotic techniquerelated information were processed. While analyzing surgical characteristics, united bowel segments and methods of anastomoses were followed. The succeeding major surgical interventions were discussed separately and for each type of surgical procedure the following aspects were evaluated: nature of anastomosis (EE - end to end, SS - side to end, ES - end to side), type of anastomosis (handsewn / stapled) and layering of the performed suture (single or double layer).
The second part focused on the effects of AL on patients postoperative evolution. During analysis of data, the center of attention turned on its influence on hospital stay, necessity of re-laparotomy, mortality and financial impact.

\section{Statistical analysis}

Collected information was processed using Microsoft Excel. The statistical analysis of the database was performed using GraphPad InStat software (GraphPad Software, Inc., San Diego, United States of America). Quantitative variables were presented by mean and median, while qualitative and categorical variables were expressed both as integer and percentage values. A normality test was applied for all variable groups in order to determine the distribution of values. Furthermore, for the quantitative statistical analysis, Student's t-test was applied for groups with Gaussian distribution of values, while Mann-Whitney nonparametric test was used for groups with non-Gaussian distribution. Inferential statistical analysis involving odd ratios determination for mentioned factors was performed using Fisher's Exact test. The level of statistical significance for the present research was set at a $p$ value of 0.05 , while the confidence interval was $95 \%$ for all the calculated parameters.

\section{Results}

Identifying the most suitable anastomotic technique for each segment of the large bowel represented the study first part primary objective. Figure 1 presents the distribution of the united bowel segments during surgical intervention. Analysis of these data evidenced entero-colonic anastomosis ( $\mathrm{n}=192)$ to be the safest $(\mathrm{OR}=0.378, \mathrm{P}=0.0086)$, while colorectal tissue fusion resulted $\mathrm{AL}$ in a significantly higher proportion $(\mathrm{OR}=3.834, \mathrm{P}=0.0017)$. Information regarding the nature of anastomosis are presented in figure 2. Stapled anastomoses were used in a greater percentage $(65.18 \%)$, while handsewn anastomosis occurred in $34.82 \%$ of cases. Evaluation of these data showed no statistical difference for the studied groups. Safety of anastomotic techniques during major surgical interventions for colorectal cancer are interpreted in table I.

\section{$\underline{\text { United bowel segments }}$}

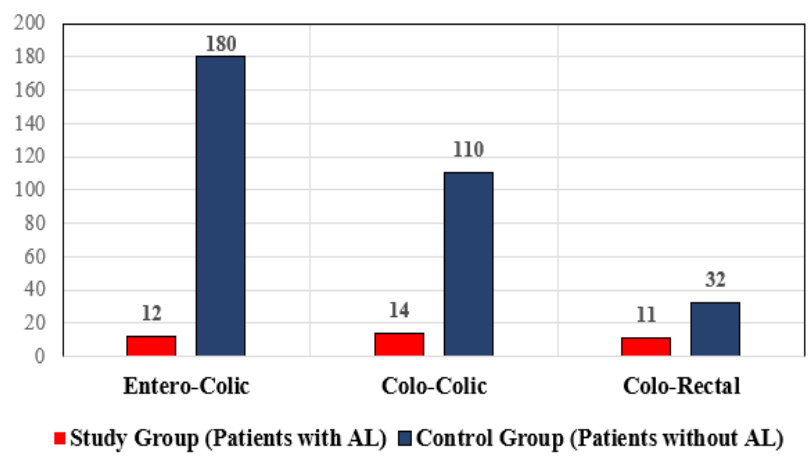

Figure 1. Fusioned endsides. 


\section{Nature of anastomosis}

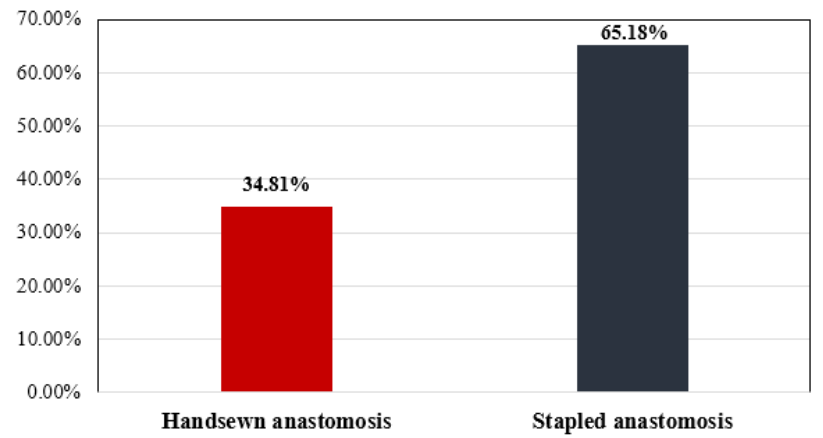

Figure 2. Tissue fusion method.

Surgical procedures for right sided colon tumors resulted in a significantly lower rate $(6 \%)$ of anastomotic leakage $(\mathrm{OR}=0.412, \mathrm{P}=0.0231)$. Analyzing the three anastomotic techniques applied for right hemicolectomy did not reveal major differences for the studied groups. End to side handsewn single layer suture presented decreased odds for fistula formation $(\mathrm{OR}=0.378)$, but without statistical significance. Meantime, side to side fusion techniques (stapled and handsewn) did not have a noteworthy influence on the appearance of AL in the postoperative period. In case of left sided colectomies, anastomotic leakage appeared in an overall of $10.71 \%$. End to end handsewn double layer anastomosis presented decreased odds regarding fistula appearance $(\mathrm{OR}=0.176)$, indicating a possible protective factor, but without statistical significance. At the time, end to end stapled technique presented increased odds ratio for postoperative fistula formation $(\mathrm{OR}=2.846)$, serving as a potential risk factor for fistula formation. Side to side mechanic suture seemed without major influence regarding postoperative complications of this nature. Throughout Reybard segmental resection, anastomosis failure appeared in $11.76 \%$ of cases. End to end anastomotic techniques (handsewn and stapled) developed low rate of fistula formation, resulting decreased odds (Handsewn - $\mathrm{OR}=0.593$, Stapled - $\mathrm{OR}=0.685$ ). Applying side to side handsewn double layer suture produced significantly more cases with AL and proved to serve as an important risk factor for this type of complication $(\mathrm{OR}=11.40, \mathrm{P}=0.0187)$. Meantime, side to side mechanic suture presented also lower chances for anastomotic leak. Regarding rectosigmoid resection, AL occurred at a higher rate (25.58\%), pointing distal anastomosis as significant risk factors for fistula formation $(\mathrm{OR}=3.834, \mathrm{P}=0.0017)$.

Tabel I. Safety of anastomoses.

\begin{tabular}{|c|c|c|c|c|}
\hline & $\begin{array}{c}\text { Study Group (Patients with } A L) \\
n=37(\%)\end{array}$ & $\begin{array}{c}\text { Control Group (Patients without } A L) \\
n=322(\%)\end{array}$ & OR & P value \\
\hline \multicolumn{5}{|l|}{ Right hemicolectomy } \\
\hline Nr. interventions performed & $9(100 \%)$ & $141(100 \%)$ & 0.412 & 0.0231 \\
\hline ES-Handsewn-Single layer & $1(11.11)$ & $35(24.82)$ & 0.378 & 0.6875 \\
\hline SS-Handsewn-Double layer & $3(33.33)$ & $36(25.54)$ & 1.458 & 0.6966 \\
\hline SS-Stapled & $5(55.56)$ & $70(49.64)$ & 1.268 & 1.0000 \\
\hline \multicolumn{5}{|l|}{ Left hemicolectomy } \\
\hline Nr. interventions performed & $6(100 \%)$ & $50(100 \%)$ & 1.053 & 1.0000 \\
\hline EE-Handsewn-Double layer & $0(0)$ & $15(30)$ & 0.176 & 0.1769 \\
\hline EE-Stapled & $3(50)$ & $13(26)$ & 2.846 & 0.3380 \\
\hline SS-Stapled & $3(50)$ & $22(44)$ & 1.273 & 1.0000 \\
\hline \multicolumn{5}{|l|}{ Reybard procedure } \\
\hline Nr. interventions performed & $8(100 \%)$ & $60(100 \%)$ & 1.205 & 0.6594 \\
\hline EE-Handsewn-Double layer & $0(0)$ & $5(8.33)$ & 0.593 & 1.0000 \\
\hline EE-Stapled & $3(37.5)$ & $28(46.67)$ & 0.685 & 0.7189 \\
\hline SS-Handsewn-Double layer & $3(37.5)$ & $3(5)$ & 11.40 & 0.0187 \\
\hline SS-Stapled & $2(25)$ & $24(40)$ & 0.500 & 0.7008 \\
\hline \multicolumn{5}{|l|}{ Dixon procedure } \\
\hline Nr. interventions performed & $11(100 \%)$ & $32(100 \%)$ & 3.834 & 0.0017 \\
\hline EE-Handsewn-Double layer & $5(45.46)$ & $10(31.25)$ & 1.833 & 0.4732 \\
\hline EE-Stapled & $6(54.46)$ & $22(68.75)$ & 0.545 & 0.4732 \\
\hline \multicolumn{5}{|l|}{ Subtotal colectomy } \\
\hline Nr. interventions performed & $3(100 \%)$ & $39(100 \%)$ & 0.640 & 0.5976 \\
\hline ES-Handsewn-Double layer & $3(100)$ & $3(7.70)$ & 73.00 & 0.0017 \\
\hline SS-Handsewn-Double layer & $0(0)$ & $3(7.70)$ & 1.490 & 1.0000 \\
\hline SS-Stapled & $0(0)$ & $33(84.60)$ & 0.027 & 0.0073 \\
\hline
\end{tabular}

$\mathrm{EE}$ - end to end. ES - end to side. $\mathrm{SS}$ - side to side. $\mathrm{AL}$ - anastomotic leakage. 
After performing Dixon type surgical interventions, anastomotic techniques seemed without influence on $\mathrm{AL}$ appearance (handsewn and stapled) in the postoperative period. Subtotal colectomy presented generally a low rate (7.14\%) of fistula formation, with decreased odds for this type of intervention $(\mathrm{OR}=0.640)$. End to side handsewn double layer technique proved to have the greatest influence on fistula formation $(\mathrm{OR}=73.00, \mathrm{P}=0.0017)$. Meantime, side to side sutures (handsewn and stapled) seemed safe choices for anastomotic procedure, with significant advance for mechanical suture $(\mathrm{OR}=0.027, \mathrm{P}=0.0073)$.

The second part of the study focused on the influence of anastomotic leakage on patients short-term postoperative outcome, underlining the possible negative effect of this unpleasant complication (Figure 3). While analyzing these aspects, we observed that postoperative fistula formation affected the length of hospitalization. Patient with AL underwent a significantly longer hospitalization in comparison with those without anastomosis related complications $(\mathrm{P}=0.0079)$. Furthermore, the necessity of surgical reintervention during hospital stay was influenced in a significant manner by the appearance of anastomosis leakage $(\mathrm{P}=0.0001)$ (Figure 4).

\section{Patients hospital stay}

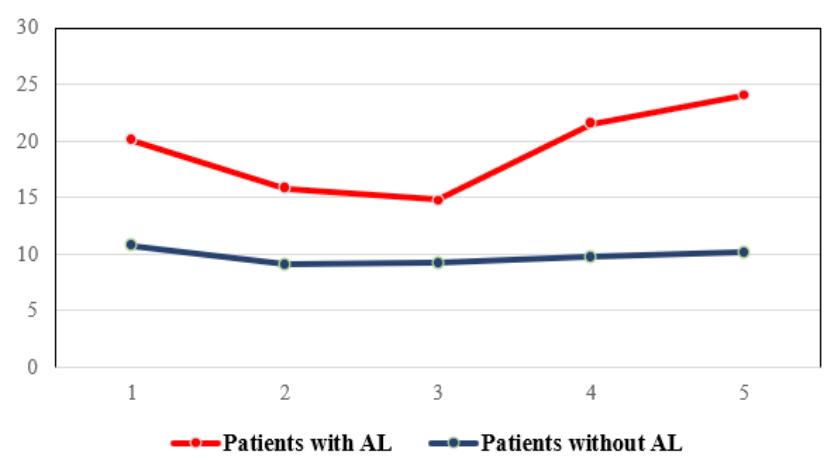

Figure 3. Influence of AL on hospital stay.

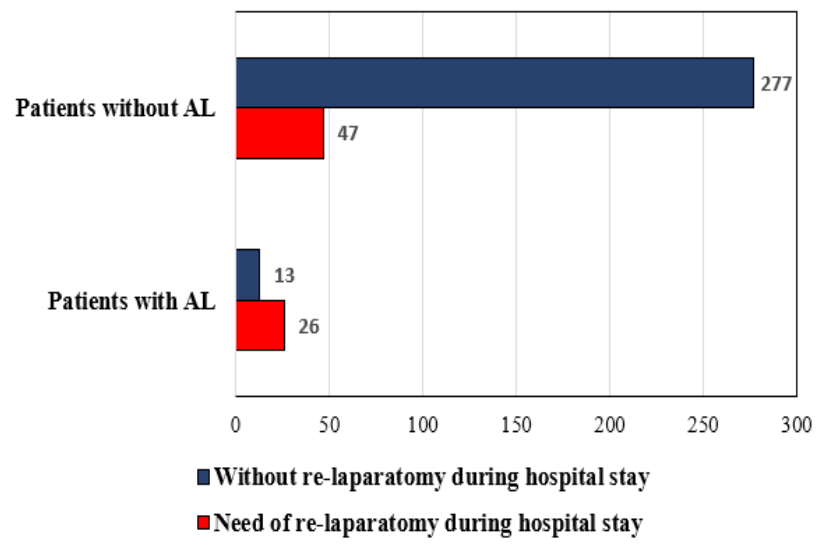

Figure 4. Influence of AL on surgical reintervention.
Patients mortality also presented our theme of investigation, being strongly affected by the development of anastomosis failure $(\mathrm{P}=0.0001)$ (Figure 5). Not least, the financial side was also investigated and was negatively affected by fistula formation, (Figure 6) patients from Study Group presented elevated hospitalization costs $(\mathrm{P}=0.0079)$.

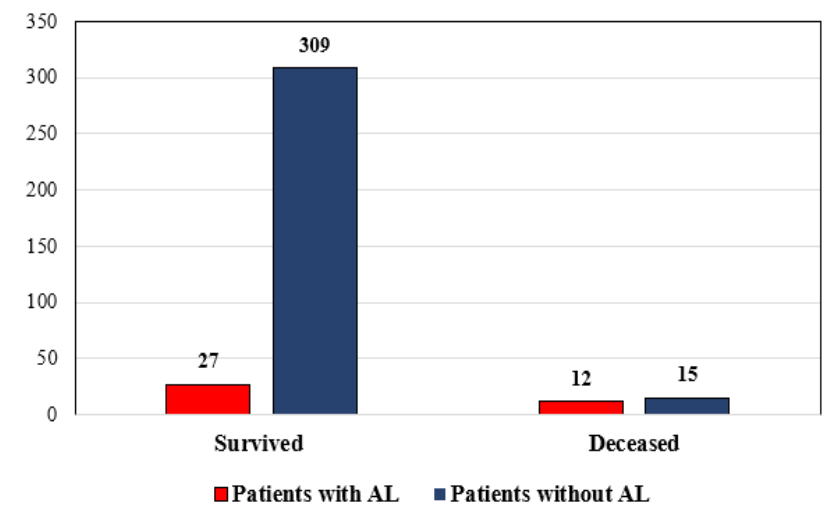

Figure 5. Influence of AL on patients mortality.

\section{Hospitalization costs of patients with CRC}

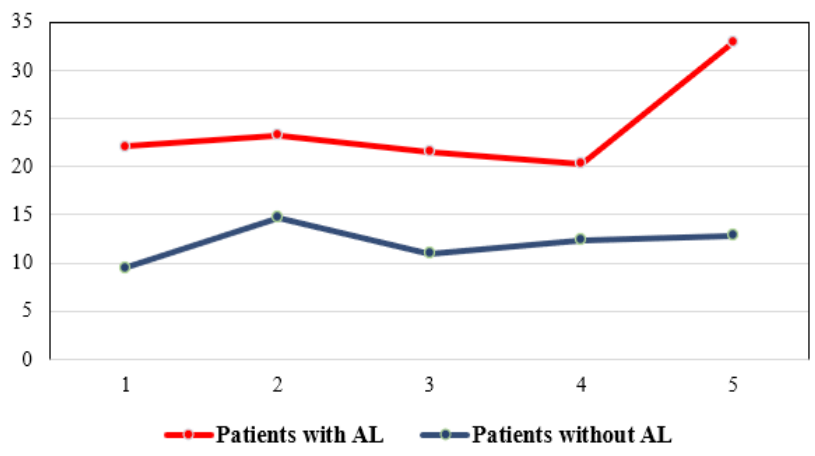

Figure 6. Financial impact of AL.

\section{Discussion}

\section{Safety of anastomotic techniques}

Due to a larger amount of right colon tumors, mostly entero-colonic anastomoses were performed, which entailed a high percentage of anastomotic leaks, as reported by other authors as well [5]. Furthermore, Akiyoshi et al. [6] highlighted that anastomosis performed on the proximal parts of the large bowel presented lower chances of AL.

Generally, mechanical anastomoses were utilized in a higher percentage over the handsewn technique, but neither of these two methods had a major influence on fistula formation. Liu et al. [7] report similar results for the two techniques with more benefits for stapled procedure.

For performing right hemicolectomy, both end to side handsewn single layer suture and side to side stapled anastomoses seemed to be a safe choice, resulting in 
decreased odds and without significant influence on fistula formation according to the present study. However, there are still controversies regarding ileo-colonic anastomosis after right hemicolectomy. According to Liu et al. [8], side to side mechanic anastomotic technique is preferred, while Nordholm-Carstensen et al. [9] sustained that stapled anastomosis had higher rates of $\mathrm{AL}$ after right colectomy. Meantime, others stated that handsewn and stapled techniques can be performed with a very low risk of anastomotic leak [10].

During left-sided colectomy, end to end handsewn double layer technique represented our primary choice, presenting the lowest influence on fistula formation during analyze of data. Likewise, Fukunaga et al. [11] preferred EE anastomotic method for colo-colonic anastomosis. For stapled methods side to side option should be considered, presenting lower incidence of anastomotic leakage in comparison with end to end type tissue fusion. In a Korean article, Han et al. [12] also opted for SS mechanic fusion of the bowel segments.

In case of sigmoid segmentary resection, both types of end to end fusion techniques (handsewn and stapled) and also side to side mechanic method seemed feasible with positive effects on the postoperative evolution. In a recent article, Kosuge et al. [13] highlighted the benefits of end to end anastomotic technique.

Rectosigmoid resection is generally associated with an increased incidence of fistula formation, independently of the anastomotic technique [14]. Ruggiero et al. [15] have also sustained that distal anastomoses are more likely to develop anastomotic failure in the postoperative period. Both handsewn and stapled methods can also be used, however mechanic technique seems more feasible due to the narrow space of the pelvic region. Goulder F in his article reported similar results with ours, recommending end to end suture for colorectal type anastomosis [16].

Evaluating subtotal colectomy, side to side technique can be performed with confidence. Meantime, end to side handsewn suture did not produce positive results. Two similar articles highlighted the benefits of SS anastomotic technique during subtotal colectomy $[17,18]$.

\section{Negative effects of anastomotic leakage}

Several studies have documented that length of hospitalization is influenced by the appearance of anastomosis failure. Patients who develop this major complication in the postoperative period, were forced to extend their hospital stay in a significant manner. Dekker et al. [19] and Iversen et al. [20] also highlighted the negative effect of anastomotic leakage on hospital stay.

In some cases, the presence of $\mathrm{AL}$ results in an increased percentage of surgical reinterventions in order to treat complications such as generalized peritonitis. According to Mik et al. [21], anastomotic failure strongly influences the incidence of re-laparotomy.

The possible fatal effect of anastomotic leakage was also emphasized during the study, patients with anastomotic leak presented a higher rate of negative postoperative evolution. Branagan et al. [22] relates also about increased mortality after suture failure, while Boccola et al. [23] set mortality for anastomotic leak between $10 \%-15 \%$. Meantime, other researchers identified mortality rate up to $29 \%$ [24].

Regarding the financial impact, development of suture failure elevated hospitalization costs in a significant manner. Due to the complexity and multidisciplinary of treatment, patients with AL presented increased costs at hospital discharge. Hammond et al. [25] emphasized a significant difference between mean costs in patients with and without anastomotic leaks, while Ribeiro et al. [26] reported 4.6 time higher hospitalization costs for patient with anastomotic leakage.

\section{Conclusion}

Performing surgical procedures in order to treat colorectal cancer, still remains a challenge, even for the most devoted surgeon as well. Postoperative complications like anastomosis leakage significantly increase hospitalization period, necessity of surgical reintervention, mortality and financial costs. In order to avoid these unpleasant events, bowel anastomoses require standardization during surgery. Tissue fusion techniques with reduced fistula formation should be chosen in order to encourage the positive postoperative evolution of patients and to reduce financial costs.

\section{References}

1. Milovanović-Alempijević T, Nikolić V, Zec S, Veljković A, Sokić-Milutinović A, Pavlović-Marković A, et al. Change in the incidence and anatomic distribution of colorectal adenoma and cancer over a period of 20 years - A single center experience. Vojnosanit Pregl. 2018;75:260-266.

2. Bakker IS, Grossmann I, Henneman D, Havenga K, Wiggers T. Risk factors for anastomotic leakage and leak-related mortality after colonic cancer surgery in a nationwide audit. Br J Surg. 2014;101:424-32; discussion 432.

3. Kim CH, Lee SY, Kim HR, Kim YJ. Nomogram prediction of anastomotic leakage and determination of an effective surgical strategy for reducing anastomotic leakage after laparoscopic rectal cancer surgery. Gastroenterol Res Pract. 2017;2017:4510561.

4. Gessler B, Eriksson O, Angenete E. Diagnosis, treatment and consequences of anastomotic leakage in colorectal surgery. Int J Colorectal Dis. 2017;32: 549-556.

5. Etele ÉE, Sala D, Dénes M, Cozlea A, Darie R, Török Á. Elderly patients with colorectal cancer - a predisposed category for postoperative complications. Chirurgia (Bucur). 2019;114:331-342.

6. Akiyoshi T, Ueno M, Fukunaga Y, Nagayama S, Fujimoto Y, Konishi T, et al. Effect of body mass index on short-term outcomes of patients undergoing laparoscopic resection for colorectal cancer: a single institution experience in Japan. 
Surg Laparosc Endosc Percutan Tech. 2011;21:409-414.

7. Liu BW, Liu Y, Liu JR, Feng ZX. Comparison of hand-sewn and stapled anastomoses in surgeries of gastrointestinal tumors based on clinical practice of China. World J Surg Oncol. 2014;12: 292.

8. Liu Z, Wang G, Yang M, Chen Y, Miao D, Muhammad S, et al. Ileocolonic anastomosis after right hemicolectomy for colon cancer: functional end-to-end or end-to-side? World J Surg Oncol. 2014;12:306.

9. Nordholm-Carstensen A, Schnack Rasmussen M, Krarup PM. Increased leaks rates following stapled versus handsewn ileocolic anastomosis in patients with right-sided colon cancer: A nationwide cohort study. Dis Colon Rectum. 2019;62:542-548.

10. Jurowich C, Lichthardt S, Matthes N, Kastner C, Haubitz I, Prock A, et al. Effects of anastomotic technique on early postoperative outcome in open right-sided hemicolectomy. BJS Open. 2019;3:203-209. doi: 10.1002/bjs5.101

11. Fukunaga $\mathrm{Y}$, Higashino $\mathrm{M}$, Tanimura S, Osugi $\mathrm{H}$. Triangulating stapling technique for reconstruction after colectomy. Hepatogastroenterology. 2007;54: 414-417.

12. Han J, Min BS. Laparoscopic-assisted radical left hemicolectomy for colon cancer. J Vis Surg. 2016;2:148.

13. Kosuge M, Eto K, Hashizume R, Takeda M, Tomori K, Neki $\mathrm{K}$, et al. Which is the safer anastomotic method for colon surgery? - Ten-year results. In Vivo. 2017;31:683-687.

14. Park JS, Choi GS, Kim SH, Kim HR, Kim NK, Lee KY, et al. Multicenter analysis of risk factors for anastomotic leakage after laparoscopic rectal cancer excision: the Korean laparoscopic colorectal surgery study group. Ann Surg. 2013;257:665-671.

15. Ruggiero R, Sparavigna L, Docimo G, Gubitosi A, Agresti M, Procaccini E, et al. Post-operative peritonitis due to anastomotic dehiscence after colonic resection. Multicentri experience, retrospective analysis of risk factors and review of the literature. Ann Ital Chir. 2011;82:369-375.

16. Goulder F. Bowel anastomoses: the theory, the practice and the evidence base. World J Gastrointest Surg. 2012;4:208213.

17. He X, Chen Z, Huang J, Lian L, Rouniyar S, Wu X, et al.
Stapled side-to-side anastomoses might be better than handsewn end-to-end anastomosis in ileocolic resection for Crohn's disease: a meta-analysis. Dig Dis Sci. 2014;59:15441551.

18. Feng JS, Li JY, Yang Z, Chen XY, Mo JJ, Li SH. Stapled sideto-side anastomosis might be benefit in intestinal resection for Crohn's disease: a systematic review and network metaanalysis. Medicine (Baltimore). 2018;97:e0315.

19. Dekker JW, Gooiker GA, Bastiaannet E, van den Broek CB, van der Geest LG, van de Velde CJ, et al. Cause of death the first year after curative colorectal cancer surgery; a prolonged impact of the surgery in elderly colorectal cancer patients. Eur J Surg Oncol. 2014;40:1481-1487.

20. Iversen H, Ahlberg M, Lindqvist M, Buchli C. Changes in clinical practice reduce the rate of anastomotic leakage after colorectal resections. World J Surg. 2018;42:2234-2241.

21. Mik M, Magdzinska J, Dziki L, Tchorzewski M, Trzcinski $\mathrm{R}$, Dziki A. Relaparotomy in colorectal cancer surgery--do any factors influence the risk of mortality? A case controlled study. Int J Surg. 2014;12:1192-1197.

22. Branagan G, Finnis D; Wessex Colorectal Cancer Audit Working Group. Prognosis after anastomotic leakage in colorectal surgery. Dis Colon Rectum. 2005;48:1021-1026.

23. Boccola MA, Buettner PG, Rozen WM, Siu SK, Stevenson AR, Stitz R, Ho YH. Risk factors and outcomes for anastomotic leakage in colorectal surgery: a single-institution analysis of 1576 patients. World J Surg. 2011;35:186-195.

24. van't Sant HP, Weidema WF, Hop WC, Lange JF, Contant $\mathrm{CM}$. Evaluation of morbidity and mortality after anastomotic leakage following elective colorectal surgery in patients treated with or without mechanical bowel preparation. Am J Surg. 2011;202:321-324.

25. Hammond J, Lim S, Wan Y, Gao X, Patkar A. The burden of gastrointestinal anastomotic leaks: an evaluation of clinical and economic outcomes. J Gastrointest Surg. 2014;18:11761185.

26. Ribiero U Jr, Tayar DO, Ribeiro RA, Andrade P, Junqueira SM Jr. The clinical and economic burden of colorectal anastomotic leaks: middle-income country perspective. Gastroenterol Res Pract. 2019;2019:2879049. 